\title{
OPTIMUM CORPORATE LEVERAGE WITH RISKY DEBT: A DEMAND APPROACH
}

\author{
Jongmoo Jay Choi \\ Temple University \\ Frank J. Fabozzi \\ Massachusetts Institute of Technology \\ Uzi Yaari \\ Rutgers University, Camden
}

\begin{abstract}
Traditional models of corporate interior optimum leverage rely on institutional schemes such as taxes, bankruptcy, and agency costs. Theories of leverage indifference in the presence of risky debt depend on various features of perfect and complete markets and on the assumption that all investors hold a uniform portfolio. In the model developed here, corporate interior optimum leverage is obtained as a result of a fundamental risk-return trade-off for investors who hold nonuniform portfolios of risky equity and debt claims in the absence of market mechanisms, forcing leverage indifference. The dynamic optimization solution accommodates bankruptcy costs and specialized institutional factors but does not rely on their presence.
\end{abstract}

\section{Introduction}

The literature responding to the Modigliani-Miller (MM) [20] leverage-indifference theorem progresses in two paths. First, studies following the examples of Hamada [12], Stiglitz [31], and Fama and Miller [8] examine the scope of the theorem under alternative sets of assumptions. Second, studies following the examples of Robichek and Myers [25] and Stiglitz [32] challenge the theorem by claiming a unique optimal leverage of the individual firm in the presence of realistic factors left out of the original model. ${ }^{1}$ This study follows the second path by investigating the firm's optimal leverage decision in an environment where the MM theorem cannot be sustained. Such a scenario may be provided by an environment that is characterized by costly and incomplete "me-first rules" $[8,13,22,26,7,30]$, costly and incomplete financial intermediaries [32], and firms whose cash streams have only imperfect substitutes $[21,7]$. Another scenario inconsistent with the MM theorem would be created by the presence of bankruptcy costs and costs of avoiding it [31, 13, 22, 32]. By focusing on the investor's choice among risky financial claims, it is shown that in the absence of

The authors would like to thank Ravi Bhushan, Scott F. Richard, and Stavros Thomadakis for their helpful comments on an earlier draft of this paper.

'Unless stated to the contrary, this paper refers to leverage indifference, or preference, at the level of the firm. Note that firm indifference does not imply economywide indeterminacy, yet firm preference implies economywide determinacy. 
extraneous market mechanisms forcing leverage indifference, market and firm equilibria imply a firm-specific leverage policy that is compatible with a unique interior leverage. This result, which is based on a pure risk-return rationale, accommodates bankruptcy costs and taxes but does not require the presence of either factor. Bankruptcy costs alone do not automatically lead to zero leverage, and a tax incentive to borrow in the absence of bankruptcy costs does not necessarily push toward 100 percent leverage. This feature of the theory presented here matches the predominance of interior leverage in reality, a phenomenon that has persisted in the face of changing tax regimes $[13,18]$.

This study follows traditional microeconomic methodology. Firm leverage decisions are viewed as a response to aggregate demands for its debt and equity claims. Aggregate demands are based, in turn, on individual investor's demands for risky debt and equity claims as components of an asset portfolio. On the supply side, traditional financial models are followed by assuming that the combined supply of debt and equity claims is constrained by the firm's operating decisions.

The analytical tool used here is the stochastic dynamic optimization technique adopted by Merton [16]. However, unlike Merton [17], Galai and Masulis [11], and Brennan and Schwartz [4], who use the same stochastic approach to extend and interpret the MM theorem, the optimization problem set up and solved here is not constrained by the MM theorem. Similar to Merton [17] and Galai and Masulis [11], but unlike Stiglitz [31], Hamada [12], and Rubinstein [28], the analysis does not depend on the separation theorem and allows investors to hold nonuniform risky portfolios that include both equity and debt claims of heterogeneous risk.

A by-product of the analysis shows that an increase in bankruptcy risk has an ambiguous effect on the value of the firm and its optimal leverage. This result is in contrast with the accepted view that bankruptcy risk decreases firm value and creates an incentive to decrease leverage.

\section{Background}

\section{Leverage Indifference}

Studies of the scope of the leverage-indifference theorem focus on three underlying assumptions: the existence of risk classes, the absence of default risk, and the implied equal access of individuals and firms to the capital market.

The original theorem assumes that the cash stream of any firm has perfect replicas in a large number of firms, which together define a "risk class." To interpret the concept of risk class and free the theorem of its dependence on the feasibility of homemade leverage arbitrage, Hamada [12] restates the theorem in terms of the SharpeLintner-Mossin CAPM. As a result, both models are extended-the MM model by quantifying the concept of risk class, and the CAPM by allowing comparison of the required return on stocks of firms that differ in their degree of leverage. Useful as it is, this synthesis sheds no light on the question of optimal leverage, since both models assume an unlimited supply of risk-free debt. 
Confronting the same issue, Stiglitz [31] demonstrates that risk classes are redundant if, as assumed by $\mathrm{MM}$, investor and firms have equal access to the market. "Equal access" means that any investor can achieve the desired degree of personal leverage by adjusting the level of borrowing on personal account under terms equal to those available to the firm. The original theorem automatically guarantees equal access through the strong assumption that debt, whether corporate or personal, is risk free. Stiglitz [31] and later Rubinstein [28] demonstrate that for the MM theorem to accommodate default risk, the "separation theorem" must hold. But this requires the restriction that all investors hold the same portfolio of risky debt and equity claims, a result criticized for internal inconsistency by Stiglitz [31] and Galai and Masulis [11]. They argue that if all investors hold the same portfolio of risky assets, they must also hold the same proportions of risky debt and equity in each firm. In the event of default, there is no redistribution of wealth and therefore no bankruptcy. Although facilitating the nominal inclusion of risky debt in the MM model, the separation theorem leaves that model empty of theoretical content. To set the condition that all investors hold the same proportions of each firm's debt and equity is to assume indifference to leverage regardless of the validity of the homemade leverage arbitrage.

An alternative approach is taken by Fama and Miller [8], who show that the MM theorem accommodates risky debt if stockholders and bondholders protect themselves from one another with perfect and costless "me-first rules." This possibility is studied by Jensen and Meckling [13] and Myers [22], who conclude that me-first rules are costly to establish and monitor, and are usually imperfect in their formulation and enforcement. Chen and Kim [5] and Smith and Warner [30] further argue that the effective cost of such rules is likely to increase with leverage.

Revisiting the same issue, Stiglitz [32] argues that the unequal costs incurred in bankruptcy causes unequal access of individuals and firms to the capital market. The higher expected bankruptcy cost of individuals leads to a break-up of the homemade leverage arbitrage, a critical ingredient in the leverage-indifference theorem. Rejecting as too strong the assumption of risk classes, Stiglitz argues that, in the face of risky debt, the theorem could be sustained only through the intervention of perfect and costless financial intermediaries - a condition that cannot be met in reality.

Rejoining the debate, Fama [7] takes the position that the MM theorem can still incorporate risky debt if the strong assumptions of equal access and perfect me-first rules are replaced by "the assumption that no firm issues securities for which there are not [numerous] perfect substitutes from other firms" (p. 272). With this assumption, which is indistinguishable from the original assumption of a "risk class," the leverageindifference theorem has come full circle.

Finally, to free the original theorem of its dependence on the exclusion of taxes, Miller [18] introduces the combined effect of corporate and personal taxes. While retaining the original assumptions of equal access with no bankruptcy costs, he replaces the specialized assumption of no taxes by the equally specialized assumption that the effective tax rate on dividends is so far below that on interest that the joint effect of the corporate and dividend taxes exactly offsets the effect of the interest tax. The result is a determinate marketwide leverage equilibrium in which the marginal personal tax rate on interest income is at par with that of corporate income, causing investor indifference toward the leverage of any single firm. The market equilibrium 
proposed by Miller leans heavily on a transitory tax regime and his interpretation of it. ${ }^{2}$ More important, the existence of market equilibrium under the revised theorem does not resolve the issue of leverage indifference at the level of the firm. In the revised version, as in the original one, firm leverage indifference requires homemade leverage arbitrage that is based on the strong condition of equal access ensured by the exclusion of bankruptcy costs.

With the exception of Stiglitz [31, 32], writers interpreting the MM theorem deemphasize the distinction between bankruptcy risk and cost. This distinction becomes unnecessary through the use of assumptions indirectly ensuring cost-free bankruptcy, should one occur. Thus, following MM, Hamada [12] uses risk-free debt; Stiglitz [31] and Rubinstein [28] set up the separation theorem, implying no transfer of ownership upon default; Fama and Miller [8] insist on perfect and costless rules for settling claims following bankruptcy; Stiglitz [32] and Fama [7] imply the absence of any dead-weight bankruptcy cost by assuming that the effect of leverage on the firm's cash stream can be fully and costlessly canceled, either by financial intermediaries (Stiglitz) or by firms of the same risk class (Fama); and Miller [18] assumes equal access to borrowing by firms and individuals. In section $\mathrm{V}$, it is argued that bankruptcy cost is inconsistent with the leverage-indifference theorem, so that "default risk" is accommodated in the afore-mentioned work only in a nominal sense. The suggested presence of bankruptcy and agency costs, as well as taxes, indicates forms of economic friction that mandate study beyond the useful abstraction of the MM theorem.

\section{Unique Leverage}

Studies claiming a unique optimal leverage of the individual firm focus on factors left out of the original MM theorem, including corporate and personal taxes, bankruptcy risk and its costs, and agency costs. Showing the way, MM [21] add a measure of institutional realism to their theory by modifying the original theorem to include the effect of corporate income tax. The leverage-indifference theorem is replaced by one showing optimality at full leverage. This result directly contradicts the observed behavior of firms.

Some researchers resolve this contradiction by introducing bankruptcy cost-a factor omitted by assumption from the MM model. Robichek and Myers [25], Baxter [2], Bierman and Thomas [3], Kraus and Litzenberger [15], and Scott [29], to name a few, argue that a unique optimal interior leverage may be reached where the constant marginal benefit from the corporate tax shield of debt equals the increasing marginal cost of expected bankruptcy. The important contribution of these studies is in the

\footnotetext{
${ }^{2}$ Miller and Scholes [19] argue that tax arbitrage allows shareholders to substitute the rate of capital gains tax for the higher rate of dividend tax, but there is no evidence that this opportunity is exploited. On the contrary, the law facilitating the alleged loophole went into effect in 1969 and, as pointed out by Feenberg [9] and Feldstein and Green [10], even since that time could not have affected more than one-tenth of 1 percent of all taxpayers receiving dividends, or 3 percent of dividend income. Indeed, Peterson, Peterson, and Ang [23] show for 1979 an average marginal personal tax on dividends of .40. Similar evidence by Poterba [24] shows limited avoidance of capital gains tax payable by individuals on common stocks. For further criticism of Miller's tax model see Barnea, Haugen, and Senbet [1].
} 
analysis of bankruptcy risk and costs, but the combination of bankruptcy costs with the effect of a corporate tax has untenable empirical implications. If the expected cost of bankruptcy increases with leverage, a zero tax rate would imply optimality of a zero leverage, while an increasing tax rate would cause an increasing leverage. Both implications are contradicted by empirical evidence [18].

This difficulty is avoided in subsequent studies by Brennan and Schwartz [4] and Kim [14]. Faced with preliminary evidence of the relative insignificance of conventional bankruptcy costs [34], these authors expand the definition of those costs by including the potential loss of the interest tax shield. ${ }^{3}$ If the corporate tax is the source of both the cost and the benefit of leverage, an increase in the tax rate may be consistent with the historical stability of leverage behavior. This argument ignores the effect of personal taxes.

Breaking with the traditional approach, Jensen and Meckling [13] and Myers [22] propose new models in which agency costs are the fundamental cause behind interior leverage. Conceptually challenging, their results seem to have had limited influence on the continuing search for a leverage decision rule.

Subsequent contributions incorporate the effect of personal taxes while paying tribute to the idea of agency costs. Chen and Kim [5] and Taggart [33] describe an interior leverage including effects of all taxes as well as bankruptcy and agency costs. DeAngelo and Masulis [6] obtain a similar result by including corporate tax shields that compete with that of the interest expense. Barnea, Haugen, and Senbet [1] achieve interior optimality by imposing on Miller's [18] model differential agency costs and individual costs of tax avoidance. Ross [27] achieves the same objective through the interaction of Miller's [18] tax regime with general uncertainty.

With the exception of agency cost models $[13,22]$, previous explanations of interior leverage rely on specialized tax assumptions that, at best, characterize the recent experience in the United States. While models of agency costs still lack in specificity, those relying on tax effects are too specific to quality as building blocks of a general leverage theory. Like agency costs models, the model presented below accommodates a variety of tax regimes because it is based on more fundamental factors determining corporate leverage decisions.

\section{A Simplified Model: The View of a Single Firm}

Consider an investor $i$ who maximizes the present value of his expected utility over time, subject to a flow-wealth constraint. By saving, this investor allocates his consumption over time; he must also make a debt-equity portfolio decision at any given time. The analysis initially concentrates on the portfolio decision concerning the secu-

${ }^{3}$ By combining bankruptcy risk with the CAPM, Kim's model is, however, subject to the same criticism as that of Rubinstein [28]: a costly bankruptcy implies risky debt that can enter the Sharpe-Lintner-Mossin CAPM only through the risky market portfolio held by all. This precludes the possibility of ownership transfer because of bankruptcy and, therefore, the possibility of a costly bankruptcy. 
rities issued by a single firm. The optimization problem calls for the allocation of wealth between debt and equity claims held in this firm, so as to maximize the derived expected utility

$$
J\left(V_{i}, t\right)=\max \int_{t}^{\infty} U_{i t}\left[C_{i}(T), T\right] d T
$$

This function is subject to the flow-wealth constraint

$$
d V_{i}=V_{i}\left[x_{i} \frac{d B}{B}+\left(1-x_{i}\right) \frac{d E}{E}\right]+\left(Y_{i}-C_{i}\right) d t
$$

where $\boldsymbol{U}_{i t}$ is a strictly concave, twice-differentiable von Neumann-Morgernstern expected utility of investor $i$ at time $t ; Y_{i}$ and $C_{i}$ are real employment income and consumption; and $V_{i}$ and $x_{i}$ are investor $i$ 's real wealth, and the proportion of it allocated to the debt of this firm. Short sales are permitted to accommodate net lending as well as net borrowing. The second argument of the utility function in (1) denotes the present value discount factor, whereas $d B / B$ and $d E / E$ in (2) stand for changes in debt and equity returns.

It is assumed that the dynamic paths of debt and equity returns are specified by the Ito process

$$
\begin{aligned}
& \frac{d B}{B}=R_{b}(B, E, t) d t+\sigma_{b}(B, E, t) d Z_{b} \\
& \frac{d E}{E}=R_{e}(E, B, t) d t+\sigma_{e}(E, B, t) d Z_{e}
\end{aligned}
$$

where, $R_{b}$ and $R_{e}$ are deterministic instantaneous expected rates of return on firm debt and equity, $\sigma_{b}$ and $\sigma_{e}$ are instantaneous standard deviations of its debt and equity returns, and $d Z$ is the Wiener process. The covariance between the two Wiener processes measures the stochastic dependence of debt and equity returns. As specified, the instantaneous returns on the two securities accommodate dependence in a most general way, including both the expected value and variance of return. This is an essential feature if the model is to represent the diverse effects of changes in basic risk, operating and financial leverages, bankruptcy costs, and taxes. For example, a change in financial leverage would affect the expected return and variance of both debt and equity claims. Further, this effect may be modified by the presence of corporate and personal taxes. Once the expected return and variance functions in (3) and (4) are specified, any such dependence would be discovered as a property of the optimal solution and the implied market equilibrium. This approach stands in sharp contrast to the MM theorem, where an a priori direct constraint is imposed on the relationship between the expected returns of firm debt and equity. 
The dynamic control solution for the optimization problem stated in equations (1)-(4) is

$$
x_{i}=\frac{1}{S^{2}}\left[\frac{R_{b}-R_{e}}{A_{i}}+h\right]
$$

where $A_{i}=V_{i} J_{V i V_{i}} / J_{V i}>0$ is the Pratt-Arrow measure of relative risk aversions, ${ }^{5}$ $S^{2}=\sigma_{b}^{2}+\sigma_{e}^{2}-2 \sigma_{b e}$ is the debt-equity portfolio variability, $h=\sigma_{e}^{2}-\sigma_{b e}$ is a "hedging" demand, and $\sigma_{b e}$ is the covariance between $d Z_{b}$ and $d Z_{e}$. The optimum demand for debt consists of a "speculative" demand dependent on the degree of risk aversion, and a "hedging" demand independent of the investor's taste for risk. In the special case of perfect risk aversion, only the latter component is relevant, and optimality is reached at the minimum variance portfolio. In general, however, both demand components enter, so that the optimal portfolio depends on the investor's degree of risk aversion. This result is compatible with an individual's portfolio composition that includes positive positions in debt and equity, a scenario indicated by $0<x_{i}<1$.

Consider now the implications of market equilibrium for the single corporation's leverage. The optimal leverage should match the market demand for its leverage, obtained by the summation of all investors' demands

$$
x \equiv D / V \equiv \sum_{i} x_{i}=\frac{1}{S^{2}}\left[\frac{R_{b}-R_{e}}{A}+h\right]
$$

subject to the definition $A=\Sigma_{i} w_{i} A_{i}$, where $w_{i}$ is the weight of investor $i$ in the market. Since $S^{2}$ increases with operating risk, this result is consistent with the accepted wisdom that optimal financial leverage is inversely related to operating risk. The maximum value of the firm commensurate with the optimal leverage is

$$
V=\frac{B}{\frac{1}{S^{2}}\left[\frac{R_{b}-R_{e}}{A}+h\right]}
$$

${ }^{4}$ The solution proceeds using the following Bellman equation

$\mathbf{\Omega}=U_{i}\left[C_{i}(t), t\right]+J_{t}+J_{V_{i}}\left[V_{i} x_{i} R_{b}+V_{i}\left(1-x_{i}\right) R_{e}\right]$

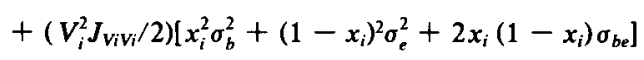

where $J_{t}$ is $J$ 's time derivative, and $J_{V}$ and $J_{V V}$ are the first and second partial derivatives of $J$ with respect to $V$. The first-order condition of $\Omega$ with respect to $x_{i}$ yields equation (5). Another first-order condition is $U_{C i}=$ $J_{v i}$; i.e., the expected marginal utility of investor $i$ from consumption is the same as from incremental wealth (saving).

${ }^{5}$ The Pratt-Arrow measure of risk aversion is useful because of the insight it provides on the relationship between wealth and attitude toward risk. The risk premium is measured locally and changes in risk are small. 
Consistent with the interpretation of (5), optimal interior leverage would be indicated by $0<x<1$ in (6) and by a positive denominator of less than unity in (7).

The significance of this result is in providing a general risk-return rationale for a firm's unique choice of interior financial leverage. Unlike the MM leverage-indifference theorem, this result does not rely on the absence of taxes or the presence of a particular tax regime. Furthermore, this result indicates uniqueness rather than indeterminacy of financial leverage, consistent with the pursuit of a leverage policy by the firm and the presence of systematic differences in the debt ratio across firms, industries, and countries, and over time. Unlike the accepted theories of interior leverage, which depend on a delicate balance between unstable tax effects and bankruptcy costs, or on the catch-all assumption of investor clientele, the present model describes this universal phenomenon in terms of fundamental risk-return characteristics. In that sense, this model explains the persistence of interior leverage through changing institutional regimes. Yet, with appropriate modifications this model can accommodate more specific cases of bankruptcy costs and taxes, as well as various types of clientele. Indeed, investor clientele based on the degree of risk aversion is already a part of this model.

\section{Expanded Model: Multifirm Equilibrium}

To facilitate comparison between the above results and those of $\mathrm{MM}$ and the CAPM, consider the case of many firms. Unlike MM, the present model does not require the strong assumption of perfect substitution in equity claims across a large number of firms within any "risk class." Unlike MM and the CAPM, this model does not assume perfect substitution in (risk-free) debt claims for all issuers. Rather, it generally permits imperfect substitution among securities issued by different firms, recognizing perfect substitution as a special case.

Specifically, assume that each of $n-1$ firms issues two types of homogeneous securities: risky debt and equity claims. The strong assumption dominating the CAPM of a zero beta or zero-variance asset in unlimited supply is replaced by the weak assumption that the $n^{\text {th }}$ firm issues zero beta claims in limited supply. These claims represent the minimum-variance portfolio with an instantaneous rate of return $R_{f}$, a special case of which is the risk-free rate. Dynamic changes in the wealth of investor $i$ can be written as

$$
\begin{gathered}
d V_{i}=V_{i}\left[\sum_{j=1}^{n-1} x_{j}\left(R_{j}-R_{f}\right)+R_{f}\right] d t+\left(Y_{i}-C_{i}\right) d t+\sum_{j=1}^{n} x_{j} V_{i} \sigma_{j} d Z_{j} \\
j=1(b, e), 2(b, e), \ldots, n-1(b, e)
\end{gathered}
$$

where asset subscript $j$ applies to both debt and equity issued by firm $j$. Investor $i$ 's optimal demand for asset $j$ is

$$
x_{i j}=\frac{1}{A_{j}} \sum_{j=1}^{n-1} V_{j k}\left(R_{j}-R_{f}\right)
$$


where $V_{j k}$ is the $j k^{\text {th }}$ element of the inverse of the variance-covariance matrix

$$
\left[S_{j k}\right]=\left[S_{b e_{j} j}\right]+\left[S_{b_{j e k}}\right]+\left[S_{b_{k e j}}\right]+\left[S_{b_{k e_{k}}}\right]+\left[S_{b_{j} b_{k}}\right]+\left[S_{e e_{k k}}\right]
$$

Aggregation of individual asset demands yields

$$
x_{j} \equiv D_{j} / V_{j} \equiv \sum_{i} x_{i j}=\frac{1}{A} \sum_{j=1}^{n-1} V_{j k}\left(R_{j}-R_{f}\right)
$$

which is the multifirm equivalent of (6). The maximum value of firm $j$ attained at the optimal leverage is

$$
V_{j}=D_{j}\left[\frac{1}{A} \sum_{j=1}^{n-1} V_{j k}\left(R_{j}-R_{f}\right)\right]^{-1}
$$

which parallels (7). This result follows from the conclusion reached above in a singlefirm setting: The unique leverages of all single firms add up to a determinate market leverage. A predominant interior leverage among single firms is translated into an interior market equilibrium leverage.

To see the relationship between this result and the asset-pricing literature, $x_{j}$ in (11) is set equal to the exogenously given proportional supplies of assets:

$$
R_{j}-R_{f}=A \sum_{j=1}^{n-1} g_{j} S_{j k}
$$

where $g_{j}$ is the ratio of the market value of risky asset $j$ to the total wealth in the economy, and $A$ is the average risk aversion, as in (6) and (7). The equilibrium assetpricing equation in reference to the market portfolio is

$$
R_{j}-R_{f}=A g \sigma_{j m} ; \quad j=1(b, e), \quad 2(b, e), \ldots, n-1(b, e)
$$

where

$$
g=\sum_{j-1}^{n=1} g_{j}
$$

and $\sigma_{j m}$ is the covariance between the return on asset $j$ and the market portfolio of risky assets. Equations (13) and (14) represent the risk-return equilibrium for the debtequity package of the individual firm in this market.

\section{The Effect of Bankruptcy Risk on Firm Value and Optimal Leverage}

Under the conventional approach to valuation, bankruptcy cost enters as a stochastic drain on a predetermined firm value. An optimum leverage is obtained by balancing the expected values of bankruptcy cost and the tax benefit of incremental 
leverage. This approach is inappropriate in the present model, where the value of the firm is stochastic as a result of the interaction between a stochastic bankruptcy cost and the valuation process. Bankruptcy risk may be introduced in the present model by specifying a structural relationship between that risk and the parameters of equations (3) and (4). These equations describe dynamic paths of debt and equity costs in a general way, allowing for deterministic and stochastic components. The effect of bankruptcy risk on the value of the firm is determined from (7)

$$
\frac{\partial V}{\partial \gamma}=\frac{\partial V}{\partial R_{b}} \cdot \frac{\partial R_{b}}{\partial \gamma}+\frac{\partial V}{\partial \sigma_{b}} \cdot \frac{\partial \sigma_{b}}{\partial \gamma}+\frac{\partial V}{\partial R_{e}} \cdot \frac{\partial R_{e}}{\partial \gamma}+\frac{\partial V}{\partial \sigma_{e}} \cdot \frac{\partial \sigma_{e}}{\partial \gamma}+\frac{\partial V}{\partial \sigma_{b e}} \cdot \frac{\partial \sigma_{b e}}{\partial \gamma}
$$

where bankruptcy risk is measured by $\gamma$, an unspecified dispersion parameter. Following the traditional treatment, the focus is on firm bondholders, ignoring any potential redistribution of wealth between them and shareholders [11]. Thus, equation (15) is restated without the last three terms

$$
\frac{\partial V}{\partial \gamma}=\frac{\partial V}{\partial R_{b}} \cdot \frac{\partial R_{b}}{\partial \gamma}+\frac{\partial V}{\partial \sigma_{b}} \cdot \frac{\partial \sigma_{b}}{\partial \gamma}
$$

Specifically, assume that each of the two parameters of debt return is an increasing function of bankruptcy risk:

$$
\frac{\partial R_{b}}{\partial \gamma}>0, \quad \frac{\partial \sigma_{b}}{\partial \gamma}>0
$$

The first assumption reflects empirical evidence that the interest rate on loans to corporations increases with borrower bankruptcy risk; the second is valid if the chance of a costly bankruptcy contributes to the overall risk sustained by creditors. It follows that the first term in (16) is strictly negative, capturing the partial effect of expected bankruptcy cost familiar from the standard analysis. However, the sign of the stochastic effect contained in the second term is generally indeterminate, indicating that the total derivative may be positive or negative. That is, the adverse effect of a higher expected bankruptcy cost may be offset or even reversed by a favorable increase in the variability of that cost. ${ }^{6}$ Only if $R_{b}<R_{e}$ is the second term negative, ensuring the standard result of an adverse bankruptcy effect. This ambiguity is overlooked in the standard analysis, which considers only the effect through the first moment (first term in (16)). This analysis would be further complicated by considering the effect of bankruptcy on equityholders.

Comparison of equations (6) and (7) reveals that the effect of bankruptcy risk on firm optimal leverage is symmetrical to the effect on its value. Given the supply of debt, $B$, an increase in expected bankruptcy cost has a partial effect of decreasing the 
optimal leverage. This effect may be offset or reenforced by the partial effect of the variability of that cost.

\section{Comparison with the MM Model and CAPM}

The difference between the MM leverage-indifference theorem and the results obtained here cannot be explained by the different assumptions concerning the riskiness of firm debt. To confirm this claim, the MM framework is followed by setting the restriction of risk-free debt in the present model. In this special case, $\sigma_{b}=0$ so that equation (6) describing the market demand for firm leverage is simplified to

$$
x=1+\frac{R_{b}-R_{e}}{A \sigma_{e}^{2}}
$$

The last expression indicates optimality of 100 percent leverage if $R_{b}=R_{e}$, of more than 100 percent (allowed by short selling) if $R_{b}>R_{e}$, but of less than 100 percent in the most likely scenario of $R_{b}<R_{e}$. The extent to which equity replaces debt depends on the value of $R_{b}-R_{e}$ relative to investors' average measure of risk aversion times the variance of equity return.

To reveal the microeconomic assumptions underlying the MM theorem, leverage indifference is set as a condition. In the present model, this condition requires perfect arbitrage between the risk-free asset and the portfolio of risky debt and equity claims. To ensure perfect substitutability between corporate and personal borrowing, such an arbitrage requires the assumption that all investors can borrow and lend funds at the same interest rate as corporations. The MM leverage arbitrage implies the equality

$$
x_{i} \frac{d B}{B}+\left(1-x_{i}\right) \frac{d E}{E}=r d t
$$

or equivalently

$$
\left[x_{i} R_{b}+\left(1-x_{i}\right) R_{e}-r\right] d t+x_{i} \sigma_{b} d Z_{b}+\left(1-x_{i}\right) \sigma_{e} d Z_{e}=0
$$

for all investors and concerning securities of all firms, where $r$ is the risk-free interest rate. The following sufficient conditions for (18b)

$$
\begin{array}{r}
x_{i} R_{b}-r=\left(x_{i}-1\right) R_{e} \\
x_{i} \sigma_{b} d Z_{b}=\left(x_{i}-1\right) \sigma_{e} d Z_{e}
\end{array}
$$

are combined to yield, for all firms, the relationship

$$
\frac{R_{e}-r}{R_{e}-R_{b}}=\frac{\sigma_{e} d Z_{e}}{\sigma_{e} d Z_{e}-\sigma_{b} d Z_{b}} \equiv \beta
$$


This equation shows that the MM theorem tacitly shares with Rubinstein's [28] version of the CAPM the strong assumption of an identical risk-return tradeoff in risky debt and equity claims for all investors. (Note that intertemporal arbitrage is implicit in the solution.)

To show that the same limitation applies to the Sharpe-Lintner-Mossin CAPM, recast (20) as

$$
R_{e}=r+\beta\left(R_{e}-R_{b}\right)
$$

This function is indistinguishable from the standard Security Market Line if: (1) $\beta$ stands for firm beta; and (2) $R_{b}=r$. This first condition is easily met if the variability of equity return is related to an exogenous market return as in the CAPM. The second condition is stipulated both in the MM model and the CAPM by their assumption of unlimited borrowing and lending at the risk-free rate. Given that the deterministic component of debt cost always equals the risk-free rate, bankruptcy can exert its influence only through the stochastic component. It follows that bankruptcy and other uncertainties are admitted in both models only as a "white noise," having no effect on expected return. That is, the MM model and its synthesis with the CAPM accept risky debt only in a nominal sense, under the strong condition that bankruptcy is cost free.

\section{Summary}

The commonly observed behavior of firms indicates that optimal financial leverage is both interior and stable. For three decades, researchers studying this behavior pattern have found it difficult to explain on purely theoretical grounds. The standard explanation claims a trade-off between the advantage of a corporate tax effect and the disadvantage of bankruptcy and agency costs. The second influential view dismisses the importance of both effects, claiming market equilibrium in which the firm is indifferent to leverage, except for serving a leverage clientele. Both approaches lean heavily on institutional factors that are less stable than the phenomenon of interior leverage. The various versions of the theory of leverage indifference also reply on one or more of the strong assumptions of perfect substitution between corporate and personal borrowing, homogeneous risk classes of firms, complete and cost-free financial intermediaries, and free and perfect "me-first rules." A realistic scenario in which none of these assumptions is satisfied is investigated in this paper. The model presented offers a fundamental explanation for the universal phenomenon of interior leverage at the level of the firm. Firm equilibrium leverage is determined by the demands of individual investors who, in the absence of a dominant risk-free asset, hold nonuniform risky portfolios chosen according to their risk-return preference. The proposed rationale for interior leverage is compatible with previous explanations but does not depend on specialized institutional assumptions. The model further provides a microeconomic building block for aggregate equilibrium analysis.

\section{References}

1. Barnea, A., R. A. Haugen, and L. W. Senbet. "An Equilibrium Analysis of Debt Financing under Costly Tax Arbitrage and Agency Problems." Journal of Finance (June 1981), pp. 569-581. 


\section{Optimum Corporate Leverage with Risky Debt}

2. Baxter, N. "Leverage, Risk of Ruin, and the Cost of Capital." Journal of Finance (September 1967), pp. 395-404.

3. Bierman, H., and J. Thomas. "Ruin Considerations and Debt Issuance." Journal of Financial and Quantitative Analysis (January 1972), pp. 1361-1378.

4. Brennan, M. J., and E. S. Schwartz. "Corporate Income Taxes, Valuation, and the Problem of Optimal Capital Structure." Journal of Business (January 1978), pp. 103-114.

5. Chen, A. H., and E. H. Kim. "Theories of Corporate Debt Policy: A Synthesis." Journal of Finance (May 1979), pp. 371-384.

6. DeAngelo, H., and R. Masulis. "Optimal Capital Structure Under Corporate and Personal Taxation." Journal of Financial Economics (March 1980), pp. 3-30.

7. Fama, E. F. "The Effects of a Firm's Investment and Financing Decisions on the Welfare of Its Security Holders." American Economic Review (June 1978), pp. 272-284.

8. Fama, E. F., and M. H. Miller. The Theory of Finance. New York: Holt, Rinehart and Winston, 1972.

9. Feenberg, D. "Does the Investment Interest Limitation Explain the Existence of Dividends?" Journal of Financial Economics (September 1981), pp. 265-269.

10. Feldstein, M. S., and J. Green. "Why Do Companies Pay Dividends?" American Economic Review (March 1983), pp. 17-30.

11. Galai, D., and R. W. Masulis. "The Option Pricing Model and the Risk Factor of Stock." Journal of Financial Economics (January/March 1976), pp. 53-82.

12. Hamada, R. S. "Portfolio Analysis, Market Equilibrium, and Corporation Finance." Journal of Finance (March 1969), pp. 13-31.

13. Jensen, M. C., and W. H. Meckling. "Theory of the Firm: Managerial Behavior, Agency Costs and Ownership Structure." Journal of Financial Economics (October 1976), pp. 305-360.

14. Kim, E. H. "A Mean Variance Theory of Optimal Capital Structure and Corporate Debt Capacity." Journal of Finance (March 1978), pp. 45-64.

15. Kraus, A., and R. H. Litzenberger. "A State-Preference Model of Optimal Financial Leverage." Journal of Finance (September 1973), pp. 911-922.

16. Merton, R. C. “Optimum Consumption and Portfolio Rules in a Continuous Time Model." Journal of Economic Theory (December 1971), pp. 373-413.

17. "On the Pricing of Corporate Debt: The Risk Structure of Interest Rates." Journal of Finance (May 1974), pp. 449-470.

18. Miller, M. H. "Debt and Taxes." Journal of Finance (May 1977), pp. 261-275.

19. Miller, M. H., and M. S. Scholes. "Dividends and Taxes." Journal of Financial Economics (December 1978), pp. 333-364.

20. Modigliani, F., and M. H. Miller. "The Cost of Capital, Corporation Finance and the Theory of Investment." American Economic Review (June 1958), pp. 261-297.

21. _ . "Corporate Income Taxes and the Cost of Capital: A Correction." American Economic Review (June 1963), pp. 433-443.

22. Myers, S. C. "Determinants of Corporate Borrowing." Journal of Financial Economics (November 1977), pp. 147-175.

23. Peterson, P. P., D. R. Peterson, and J. S. Ang. "Direct Evidence on the Marginal Rate of Taxation on Dividend Income." Journal of Financial Economics (March 1985), pp. 267-282.

24. Poterba, J. M. “How Burdensome Are Capital Gains Tax?” National Bureau of Economic Research, Working Paper No. 1871, March 1986.

25. Robichek, A. A., and S. C. Myers. Optimal Financing Decisions. Englewood Cliffs, N.J.: PrenticeHall, 1965.

26. Ross, S. A. "The Determination of Financial Structure: The Incentive Signalling Approach." Bell Journal of Economics (Spring 1977), pp. 23-40. ."Debt and Taxes and Uncertainty." Journal of Finance (July 1985), pp. 637-657. 
28. Rubinstein, M. "A Mean-Variance Synthesis of Corporate Financial Theory." Journal of Finance (March 1973), pp. 167-181.

29. Scott, J. H. "A Theory of Optimal Capital Structure." Bell Journal of Economics and Management Science (Spring 1976), pp. 33-54.

30. Smith, C. W., and J. B. Warner. "On Financial Contracting: An Analysis of Bond Covenants." Journal of Financial Economics 7 (1979), pp. 117-161.

31. Stiglitz, J. "A Re-Examination of the Modigliani-Miller Theorem." American Economic Review (December 1969), pp. 784-793.

32. . “On the Relevance of Corporate Financial Policy." American Economic Review (December 1974), pp. 851-866.

33. Taggart, R. A. "Taxes and Corporate Capital Structure in an Incomplete Market." Journal of Finance (June 1980), pp. 645-659.

34. Warner, J. B. “Bankruptcy Costs: Some Evidence." Journal of Finance (May 1977), pp. 337-347. 